\title{
Correlations of lung morphology, pulmonary vascular resistance, and outcome in children with congenital heart disease
}

\author{
A BUSH, C M BUSST, S GHAWORTH, * A A HISLOP, * W B KNIGHT, B CORRIN, \\ E A SHINEBOURNE \\ From the Brompton Hospital, Cardiothoracic Institute and ${ }^{\star}$ Institute of Child Health, London
}

SUMMARY Pulmonary vascular resistance was measured in air, oxygen, and after administration of vasodilators in 14 children with pulmonary hypertension and congenital heart disease. Lung morphology was examined by light microscopy and assessed quantitatively. In this selected group of patients (a) medial muscle thickness of $>20 \%$ in the intra-acinar arteries and Heath-Edwards changes of I or II were significantly associated with perioperative death from pulmonar complications after cardiac surgery; $(b)$ children with lower percentage medial muscle thickness. had a higher baseline resistance $(r=-0 \cdot 84)$ associated with Heath-Edwards grade III or highe $\Phi_{\infty}^{\circ}$ changes (most of these patients were not offered corrective sugery); (c) when the lowest pulmonary vascular resistance was $<3$ units, Heath-Edwards grading was I or II $(n=4)$. When the pulmonary vascular resistance was $>6$ units, however, there was no direct correlation with Heath Edwards grading $(n=9)$. Four patients with a resistance of $>6$ units had only grade I or I I changes. Three had a medial muscle thickness above $20 \%$, and were among those who died at o $\frac{2}{2}$ soon after operation.

It is concluded that $(a)$ patients with a lowest pulmonary vascular resistance of $>6$ units have $\frac{0}{8}$ bad prognosis whatever their lung morphology; and $(b)$ some patients with Heath-Edwards grade I or II will have a high resistance (this group has a high medial muscle mass and a poor prognosis and would not be detected by Heath-Edwards grading alone).

Many congenital heart defects can be corrected surgically during childhood, but the timing of operation is important because progressive damage to the pulmonary circulation may make anatomical correction impossible. Many techniques have been used to assess pulmonary circulatory damage, including assessment of haemodynamic function, ${ }^{12}$ pulmonary wedge angiography, ${ }^{3}$ and lung biopsy. ${ }^{4-6}$ The purpose of this study was to try to define the relation between lung morphology, measurements of pulmonary vascular resistance, and outcome.

\section{Patients and methods}

PATIENTS

At the Brompton Hospital pulmonary vascular resistance in air and $100 \%$ oxygen is measured in

Requests for reprints to Dr E A Shinebourne, Brompton Hospital, Fulham Road, London SW3 6HP.

Accepted for publication 26 November 1987 children with suspected pulmonary vascular disease Those with resistances of between 4 and 10 Woog Units (mm Hg. $1^{-1} \cdot \min . \mathrm{m}^{2}$ ) have a lung biopsyo Biopsy is also performed if there are clinical grounds to doubt the feasibility of operation. We have reviewed 14 patients studied over a seven year periof in whom full physiological and histological data are. available. Table 1 gives their details and diagnoses Lung tissue was obtained at biopsy $(n=9)$ or necropsy $(n=5)$. Informed consent was obtaine\& for all procedures, usually from the parents, and aff research protocols were approved by the Bromptor Hospital Ethics Committee.

\section{METHODS}

Measurement of pulmonary vascular resistance

Pulmonary vascular resistance was calculated fror pulmonary blood flow measured by the direct Fic $\overline{8}$ principle. Oxygen consumption was measured by mass spectrometry. Full details of the method have् been published..$^{78}$ Measurements were usually madg 
Table 1 Details and diagnoses of patients studied (arranged in ascending order of baseline pulmonary vascular resistance)

\begin{tabular}{|c|c|c|c|c|c|c|}
\hline No & Sex & $\begin{array}{l}\text { Height } \\
\text { (centile) }\end{array}$ & $\begin{array}{l}\text { Weight } \\
\text { (centile) }\end{array}$ & Diagnosis & $\begin{array}{l}\text { Age at } \\
\text { first catheter }\end{array}$ & $\begin{array}{l}\text { Age at } \\
\text { lung biopsy/necropsy }\end{array}$ \\
\hline $\begin{array}{r}1 \\
2 \\
3 \\
4 \\
5 \\
6 \\
7 \\
8 \\
9 \\
10 \\
11 \\
12 \\
13 \\
14\end{array}$ & $\begin{array}{l}\mathbf{F} \\
\mathbf{M} \\
\mathbf{M} \\
\mathbf{F} \\
\mathbf{M} \\
\mathbf{F} \\
\mathbf{M} \\
\mathbf{F} \\
\mathbf{F} \\
\mathbf{M} \\
\mathbf{F} \\
\mathbf{F} \\
\mathbf{F} \\
\mathbf{F}\end{array}$ & $\begin{array}{r}<3 \\
10 \\
33 \\
<3 \\
10 \\
25 \\
25 \\
<3 \\
50 \\
35 \\
30 \\
80 \\
<3 \\
3\end{array}$ & $\begin{array}{r}<3 \\
<3 \\
<3 \\
<3 \\
25 \\
30 \\
<\quad 3 \\
3 \\
50 \\
<3 \\
30 \\
60 \\
<3 \\
<3\end{array}$ & $\begin{array}{l}\text { AVSD, PDA, DS } \\
\text { VSD, DS } \\
\text { DORV, MA } \\
\text { VSD, PDA, PAB, C } \\
\text { AVSD, DS } \\
\text { VSD } \\
\text { VSD, PDA, PAB, C } \\
\text { VSD, PDA, C } \\
\text { TGA, VSD, PAB } \\
\text { LVOTO, MS, EFE } \\
\text { ASD (S) } \\
\text { ASD (S) } \\
\text { AVSD, MR } \\
\text { VSD }\end{array}$ & $\begin{array}{l}13 \text { mnth } \\
9 \text { mnth } \\
10 \text { yr } 10 \text { mnth } \\
5 \text { mnth } \\
3 \text { yr } 4 \text { mnth } \\
7 \text { yr } 8 \text { mnth } \\
2 \text { mnth } \\
15 \text { mnth } \\
2 \text { yr } 5 \text { mnth } \\
13 \text { mnth } \\
19 \text { yr } 4 \text { mnth } \\
2 \text { yr } 3 \text { mnth } \\
16 \text { mnth } \\
8 \text { yr } 8 \text { mnth }\end{array}$ & $\begin{array}{l}13 \text { mnth } \\
9 \text { mnth } \\
10 \mathrm{yr} 11 \text { mnth } \\
6 \mathrm{mnth} \\
3 \mathrm{yr} 4 \mathrm{mnth} \\
7 \mathrm{yr} 8 \mathrm{mnth} \\
2 \mathrm{mnth} \\
18 \mathrm{mnth} \\
2 \mathrm{yr} 5 \mathrm{mnth} \\
13 \mathrm{mnth} \\
19 \mathrm{yr} 2 \mathrm{mnth} \\
2 \mathrm{yr} 3 \mathrm{mnth} \\
16 \mathrm{mnth} \\
12 \mathrm{yr} 4 \text { mnth }\end{array}$ \\
\hline
\end{tabular}

ASD(S), ostium secundum atrial septal defect; AVSD, atrioventricular septal defect; C, coarctation; DORV, double outlet right ventricle; DS, Down's syndrome; EFE, endocardial fibroelastosis; LVOTO, left ventricular outflow tract obstruction; MA, mitral atresia; MR, mitral regurgitation; MS, mitral stenosis; PAB, pulmonary artery banding; PDA, patent arterial duct; TGA, transposition of great arteries; VSD, ventricular septal defect.

with the patients ventilated both on air and $100 \%$ oxygen. When necessary epoprostenol (prostacyclin) was given by continuous intravenous infusion at rates of $5-20 \mathrm{ng} / \mathrm{kg} / \mathrm{min}^{9}$ and a bolus of tolazoline (1-2 $\mathrm{mg} / \mathrm{kg}$ ) was given into the pulmonary artery. ${ }^{10}$

\section{Assessment of lung morphology}

The lung tissue was reviewed without knowledge of the clinical details or resistance measurements. The abnormalities were graded according to the HeathEdwards classification, ${ }^{4}$ modified to include the predilatation phase. ${ }^{11-13}$ For the quantitative studies, the mean number of arteries measured in each specimen was 35 , range $20-55$. The mean percentage arterial medial thickness was calculated and compared with the normal values for age ${ }^{6}$ by nonorthogonal analysis of variance. The normal values were derived from non-injected, postmortem material. The mean external diameter and muscularity of the arteries accompanying the different airway generations was determined and compared with age matched controls. The ratio of patent intra-acinar arteries to alveoli was calculated to compensate for differences in the degree of inflation in different lungs. The alveolar/arterial ratio was not determined in specimens showing generalised arterial dilatation.

\section{Results}

\section{PULMONARY VASCULAR RESISTANCE} MEASUREMENTS

Table 2 summarises the haemodynamic data. The group mean baseline pulmonary blood flow was $5.91 / \mathrm{min} / \mathrm{m}^{2}$ (range $0.6-14.0$ ) and mean pulmonary vascular resistance was $10 \cdot 1$ Wood units (range $2 \cdot 1-24 \cdot 6$ ). Even in patients with high pulmonary vascular resistances, $100 \%$ oxygen, epoprostenol, or tolazoline produced vasodilatation. This was usually

Table 2 Mean pulmonay artery pressure ( $P A P, m m ~ H g)$, pulmonary blood flow $\left(Q p, l / m i n / m^{2}\right)$, and pulmonary vascular

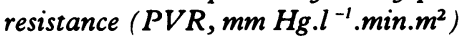

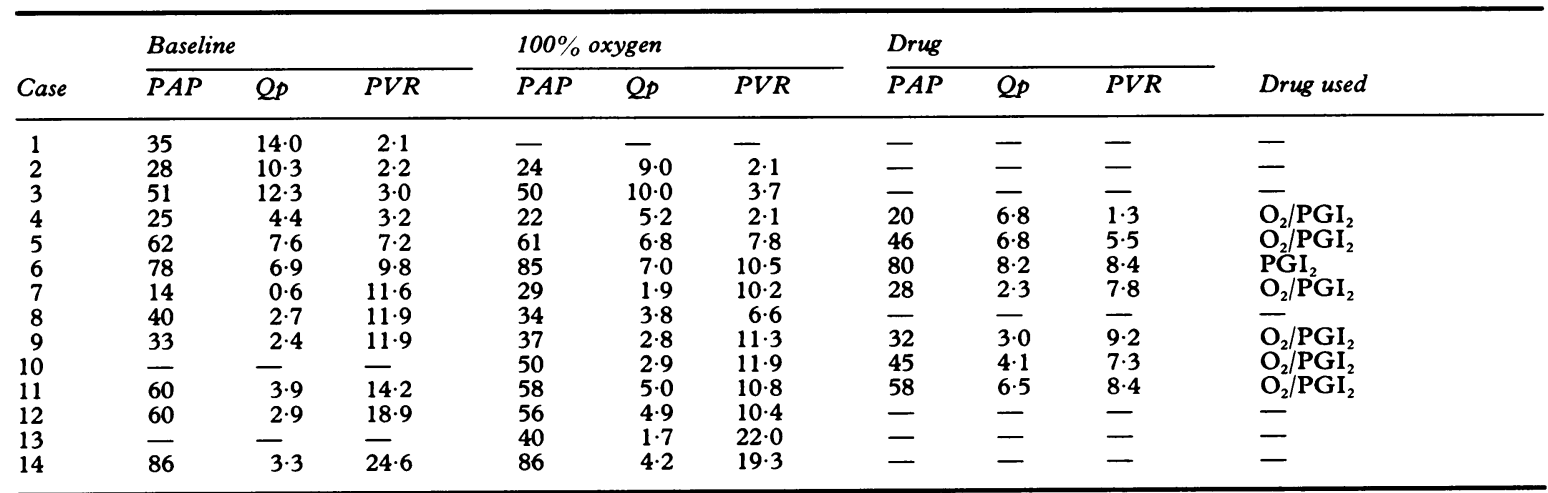

$\mathrm{O}_{2}, 100 \%$ oxygen; $\mathrm{PGI}_{2}$, epoprostenol (prostacyclin). 


\begin{tabular}{|c|c|c|c|c|c|c|c|}
\hline \multirow[b]{2}{*}{ No } & \multirow[b]{2}{*}{ Tissue } & \multirow{2}{*}{$\begin{array}{l}\text { Preacinar } \\
I P / I F\end{array}$} & \multicolumn{4}{|c|}{ Intra-acinar arteries } & \multirow[b]{2}{*}{ Grade PVD } \\
\hline & & & $E x t / D i l$ & $\% M W T^{\star}$ & Size & No† & \\
\hline $\begin{array}{l}1 \\
2 \\
3 \\
4 \\
5 \\
6 \\
7 \\
8 \\
9\end{array}$ & $\begin{array}{l}\text { PM } \\
\text { PM } \\
\text { LB } \\
\text { LB } \\
\text { LB } \\
\text { LB } \\
\text { LB } \\
\text { LB } \\
\text { LB }\end{array}$ & $\begin{array}{l}+ \\
+ \\
0 \\
0 \\
+ \\
+ \\
+ \\
+ \\
+\end{array}$ & $\begin{array}{l}\text { Ext } \\
\text { Ext } \\
\text { Ext } \\
\text { Ext } \\
\text { Ext } \\
\text { Ext } \\
\text { Ext } \\
\text { Dil } \\
\text { Ext } \pm \\
\text { Dil } \pm\end{array}$ & $\begin{array}{l}24 \ddagger \\
36 \ddagger \\
26 \ddagger \\
30 \ddagger \\
20 \ddagger \\
22 \ddagger \\
15 \ddagger \\
10 \\
13\end{array}$ & $\begin{array}{l}\mathbf{N} \\
\mathbf{I} \\
\mathbf{D} \\
\mathbf{N} \\
\mathbf{I} \\
\mathrm{D} \\
\mathbf{I} \\
\mathbf{I} \\
\mathbf{N}\end{array}$ & $\begin{array}{c}- \\
6 \cdot 1 \\
16 \\
9 \cdot 1 \\
10 \cdot 5 \\
9 \cdot 8 \\
8 \\
6\end{array}$ & $\begin{array}{l}\text { I-II } \\
\text { II } \\
\text { I-II } \\
\text { I } \\
\text { III } \\
\text { III late } \\
\text { II } \\
\text { III predil } \\
\text { III predil }\end{array}$ \\
\hline $\begin{array}{l}10 \\
11 \\
12 \\
13 \\
14\end{array}$ & $\begin{array}{l}\text { PM } \\
\text { LB } \\
\text { PM } \\
\text { LB } \\
\text { PM }\end{array}$ & $\begin{array}{l}\mathrm{O} \\
\mathrm{O} \\
+ \\
\stackrel{+}{O} \\
+ \text { plex }\end{array}$ & $\begin{array}{l}\text { Ext } \\
\text { Ext } \\
\text { Dil } \\
\text { Ext } \\
\text { Dil }\end{array}$ & $\begin{array}{c}37 \ddagger \\
8 \\
6 \\
37^{\star} \\
11\end{array}$ & $\begin{array}{l}\mathbf{N} \\
\mathbf{N} \\
\mathbf{N} \\
\mathbf{D} \\
-\end{array}$ & $\begin{array}{c}9 \cdot 2 \\
10 \\
9 \cdot 6 \\
-\end{array}$ & $\begin{array}{l}\text { I-II } \\
\text { II } \\
\text { III predil } \\
\text { I-II } \\
\text { IV }\end{array}$ \\
\hline
\end{tabular}

$\star$ Normal mean value $7 \cdot 4$. $†$ Normal range $8 \cdot 2-11 \cdot 2$

$\ddagger$ Significantly greater than normal.

LB, lung biopsy; PM, lung tissue obtained at necropsy; predil, pre-dilatation; IP/IF, intimal proliferation/fibrosis; \% MWT, percentage $\stackrel{\circ}{\supset}$ arterial medial thickness in arteries $50-100 \mu \mathrm{m}$ in diameter; grade PVD, grade of pulmonary vascular disease; $D$, decreased; I, increased; $O$, not available; Ext, extension of arterial medial thickness into more peripheral arteries than normal; Dil, dilatation; plex, plexiform $\square$ lesions.

manifested by an increase in flow with unchanged pulmonary artery pressure. The mean fall in pulmonary vascular resistance with $100 \%$ oxygen was 2.2 units (range -0.7 to $5.3, \mathrm{p}<0.02, \mathrm{n}=11$ ) and the mean additional fall in resistance with a bloodborne vasodilator was 2.3 units (range 0.8 to $4.3, \mathrm{p}<0.001, \mathrm{n}=10$ ).

\section{LUNG MORPHOLOGY}

All 14 patients showed an increase in pre-acinar (proximal to the respiratory unit) arterial medial thickness and ten showed extension of muscle into more peripheral arteries than normal. In nine of the ten patients this was associated with a significant increase in intra-acinar percentage arterial medial thickness (table 3 ). The four patients who did not show this extension did not have an increase in intraacinar medial thickness and the intra-acinar arteries appeared to be dilated. In these cases the structural abnormalities present in both the pre- and intraacinar arteries were characteristic of grade IV pulmonary vascular disease $(n=1)$ (HeathEdwards) or of the predilatation phase $(n=3) \cdot{ }^{11-13}$ In three children there was a reduction in the mean external diameter of the arteries accompanying respiratory bronchioli. In two patients this reduction in intra-acinar size was probably accounted for by their small body size for age. Only case 3 had an abnormally high alveolar/arterial ratio, indicating a reduction in the number of intra-acinar arteries.

\section{CORRELATION OF HAEMODYNAMIC AND}

MORPHOMETRIC DATA

Pulmonary vascular resistance measured when the patients were breathing air (baseline pulmonary $\stackrel{\infty}{\infty}_{\infty}^{\infty}$ vascular resistance) was lowest in those with the greatest percentage arterial medial thickness (AMT) in arteries that were $50-100 \mu \mathrm{m}$ in diameter (pulmonary vascular resistance $=-0 \cdot 60 . \mathrm{AMT}+\stackrel{0}{0}$ $21.5, r=-0.84, p<0.002$, fig 1$)$. The fall in $\frac{0}{\mathbb{D}}$ pulmonary vascular resistance when vasodilators $\cong$ were given (baseline minus lowest pulmonary음 vascular resistance) was greatest in those with the highest resistances, and hence in those who had the lowest percentage arterial medial thickness (change

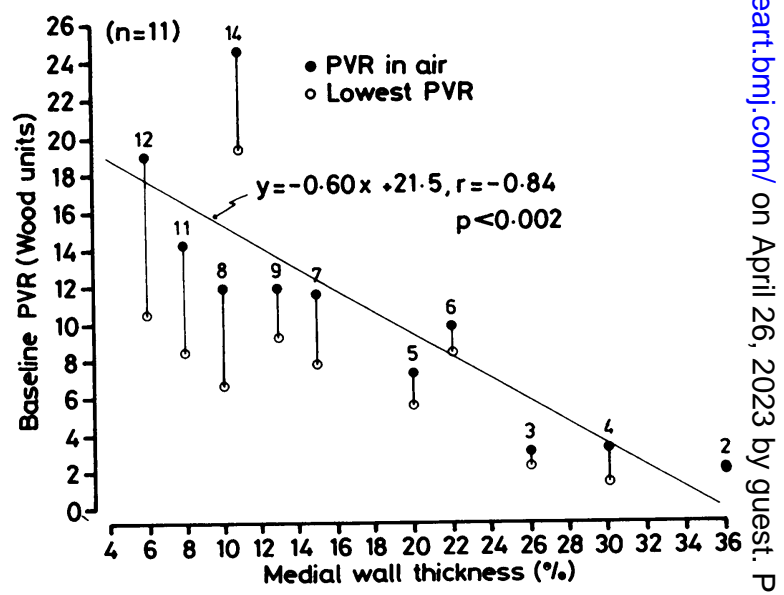

Fig 1 Medial wall thickness of intra-acinar arteries plotted ${ }_{\vec{D}}$ against pulmonary vascular resistance (PVR). The figure is based on the 11 patients for whom data on baseline PVR, and $\stackrel{\AA}{\AA}$ fall in PVR after vasodilators (reversibility) are shown. The line is the regression of baseline resistance on medial wall thickness. The numbers identify the patients. 


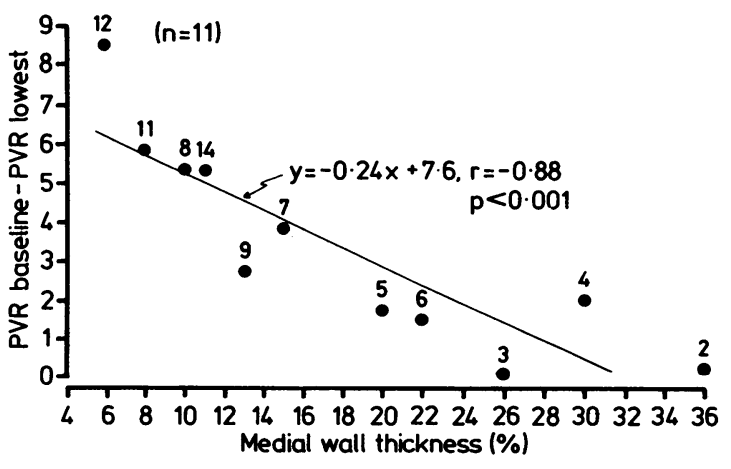

Fig 2 Medial wall thickness of intra-acinar arteries plotted against change in pulmonary vascular resistance (PVR baseline-PVR lowest). The figure is based on the 11 patients for whom baseline and reversibility data are available. The numbers identify the patients.

in pulmonary vascular resistance $=-0 \cdot 24$. AMT $+7 \cdot 6, r=-0.88, p<0.001$, fig 2). Pulmonary blood flow was highest in those with the greatest percentage arterial medial thickness (flow $=0.27 . \mathrm{AMT}+0.38, \mathrm{r}=0.72, \mathrm{p}<0.02$, fig 3). Change in blood flow (highest minus baseline) did not correlate with medial muscle thickness (fig 4). No haemodynamic measurement correlated with the number of intra-acinar arteries.

Figure 5 shows the relation between baseline and lowest pulmonary vascular resistance and the histological grading of the biopsy specimens by the modified Heath-Edwards classification. A lowest pulmonary vascular resistance of $<3$ units was

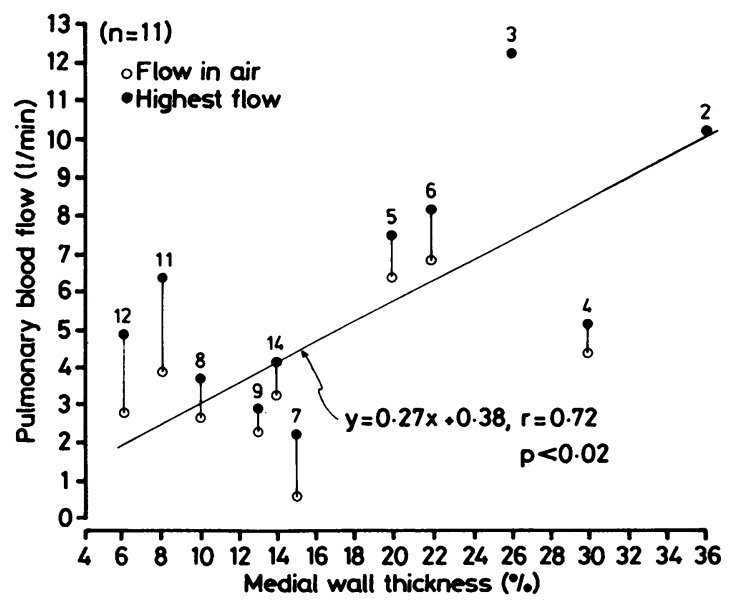

Fig 3 Medial wall thickness of intra-acinar arteries plotted against pulmonary blood flow. The figure is based on the 11 patients for whom baseline and reversibility data are available. The line is the regression of baseline flow on medial wall thickness. The numbers identify the patients.

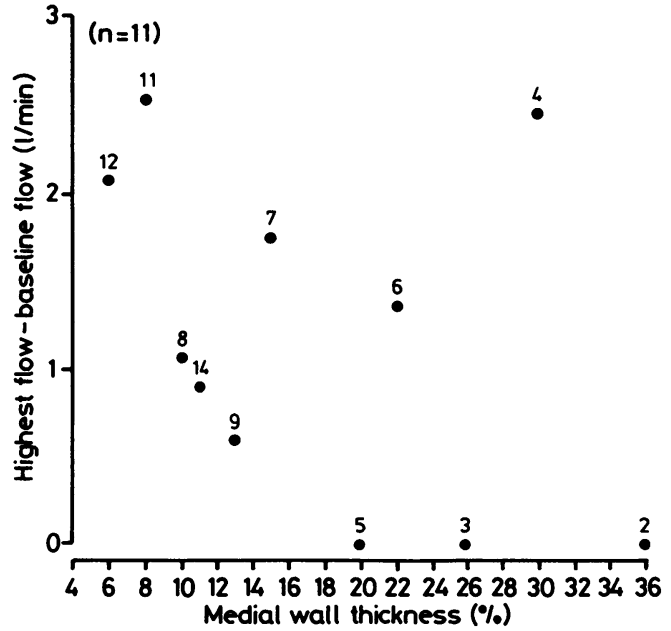

Fig 4 Medial wall thickness of intra-acinar arteries plotted against change in pulmonary blood flow (highest minus baseline). The figure is based on the 11 patients for whom baseline and reversibility data are available. The numbers identify the patients.

associated with grade I or II changes $(n=4)$. The single case with early grade III changes had a lowest resistance of 5.5 units. When the resistance was $>6$ units there was no correlation with the HeathEdwards classification. Five patients had disease that was late grade III or worse, and in the remaining four cases the pulmonary vascular abnormalities were less severe (grade I/II) than expected.

\section{OUTCOME}

Six of seven patients in whom corrective cardiac surgery was attempted died within a week of operation (cases $1-3,5,10$, and 12). Child 13 died within hours of his lung biopsy. The notes were reviewed retrospectively without knowledge of the resistance or morphometric measurements. Pulmonary vasoconstriction or structural pulmonary vascular disease were considered to be major factors contributing to all the deaths. The only physiological or histological measurement that was predictive of perioperative death was an arterial medial thickness of $\geqslant 20 \%$ ( $p<0.05$, Fisher's exact probability test, one tailed). Of the other six patients, two died of progressive right heart failure (patients 7 and 14). Patients 4 and 6 remain well two years after investigation. Patient 8 had ligation of the arterial duct and repair of coarctation: the ventricular septal defects were left open, but subsequently closed spontaneously, and she remains well. Patient 9 had a palliative Mustard's procedure without closure of the ventricular septal defects; she is well but becomes cyanosed on exertion. 


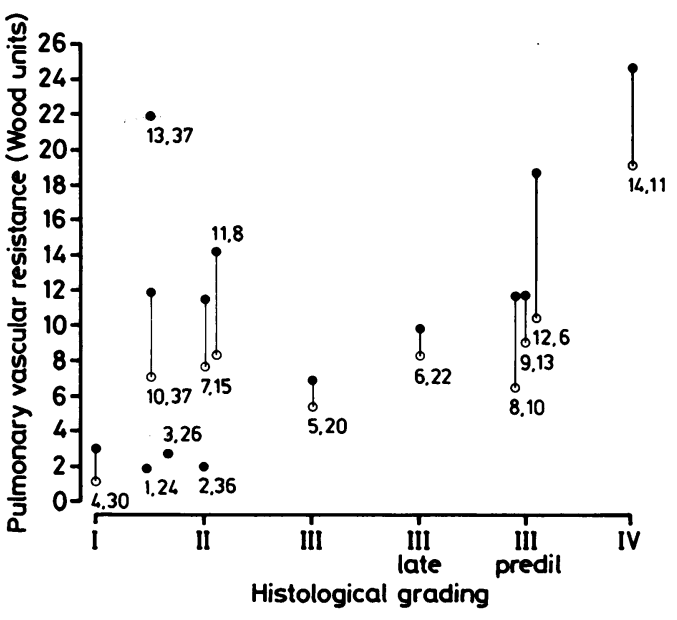

Fig 5 Heath-Edwards grading, modified to include the predilatation phase (III predil) plotted against pulmonary vascular resistance. The numbers are the patient number and the medial wall thickness of intra-acinar arteries $(\%)$ respectively. $\bullet$, baseline resistance; $\bigcirc$, lowest resistance.

\section{Discussion}

These patients represent a highly selected group, varying in age, type of cardiac anomaly, and severity of pulmonary vascular disease. The proportion of patients with a pulmonary vascular resistance of at least $5 \cdot 5$ units $(10 / 14)$ and coming to necropsy (5/14) indicates that the severe disease/high risk end of the spectrum is overrepresented in this series. Outcome was not an independent variable, because management was based on the interpretation of the data available at the time. We report these patients because we have both accurate measurements of pulmonary vascular resistance and reactivity as well as detailed lung morphology.

Measurement of pulmonary blood flow by the direct Fick principle depends on direct measurement of oxygen consumption. Many investigators, however, rely on tables of predicted values, which are unreliable. ${ }^{14}{ }^{15} \mathrm{It}$ is also important to distinguish fixed anatomical damage from reversible pulmonary vasoconstriction, otherwise the child may be denied a potentially curative operation. We routinely use at least one of $100 \%$ oxygen, epoprostenol, and tolazoline as pulmonary vasodilators when the resistance is raised. Details of interactions between these agents can be found elsewhere. ${ }^{910}$

We compared measurements of percentage arterial medial thickness with outcome after cardiac surgery. In the immediate postoperative period six died of pulmonary circulatory disease. A percentage arterial medial thickness of $>20 \%$ was associated with perioperative death after cardiac surgery ( $p<0.05)$. This confirms the findings of others. ${ }^{911}$ Patients with only slightly increased medial thickness had associated grade III or worse Heath-Edwards changes, and most were not offered corrective surgery. The only death after lung biopsy (case 13) was in the infant with the highest percentage arterial medial thickness. Perhaps even minor surgical procedures carry an increased risk if the percentage arterial medial thickness is high.

Despite this, baseline pulmonary vascular resistance showed a negative correlation with percentage arterial medial thickness (fig 1) and baseline flow a slightly less good positive correlation (fig 3) in the 11 patients in whom baseline pulmonary vascular resistance and pulmonary vascular resistance after vasodilators had been given were known. This relation has been described before. ${ }^{916}$ The better agreement reported here is probably because pulmonary blood flow was measured directly rather than estimated from assumed values of oxygen consumption. It may seem surprising that a high resistance is associated with normal or only mildly increased arterial medial wall thickness. Serial reconstruction studies in other patients, however, have shown high resistance to be caused by associated severe proximal obstruction. ${ }^{11}{ }^{17}$ It is likely that smooth muscle regresses as flow and pressure drop distal to such obstructions-this is analagous to the regression of smooth muscle distal to a surgically placed pulmonary artery band.

We have also shown that patients with normal or only modestly increased arterial medial muscle and high resistances show a much greater absolute drop in resistance when they are given vasodilators than those with greatly increased arterial muscle and normal or only modestly increased resistance (fig 2 ). It seems paradoxical that the less arterial muscle present, the greater the reversibility. If resistance is determined by very narrow proximal vessels, however, even a small percentage increase in the lumens of such vessels will reduce resistance considerably. When there is increased muscle in distal vessels, the pulmonary vascular resistance is lower than when the obstruction is more proximal, leaving less scope for a fall in resistance with vasodilators.

We also looked at the relation between lowest pulmonary vascular resistance and the modified Heath-Edwards grading (fig 5). The Heath-Edwards classification does not include a pre-dilatation phase, which is therefore likely to be misdiagnosed as grade II or early grade III. If this phase is omitted, the agreement between pulmonary vascular resistance and grading is less good. The high resistances 
measured in three patients independently classified as being in the pre-dilatation phase by histological grading supports the view that this phase is a clinically important addition to the Heath-Edwards classification. The finding of inoperable pulmonary vascular disease in patients with resistances as low as 6 units is surprising, since much higher values have been reported as compatible with operability. ${ }^{12}$ These values may be higher because of failure to measure pulmonary vascular resistance accurately because oxygen consumption was only assumed. Another factor may be failure to administer appropriate vasodilators. In doubtful cases it is important to administer both $100 \%$ oxygen and a bloodborne agent to determine the lowest pulmonary vascular resistance. ${ }^{910}$

In four of 14 cases the pulmonary vascular resistance was higher than expected from the histological grading. It is thus difficult to know how to manage patients with a lowest resistance of $>6$ units, in whom there is no correlation between measured resistance and Heath-Edwards grading. Some will have inoperable pulmonary vascular disease, whereas others will have an apparently benign histological examination. Of the four patients in this latter group, patient 13 died after a lung biopsy, patient 10 died soon after corrective surgery, and patient 7 died of progressive cardiorespiratory failure several months after palliative operation. These three patients had an increased arterial medial thickness, which may not always permit successful operation. ${ }^{11}$ The fourth patient had an isolated atrial septal defect closed without complications, and clinically her pulmonary hypertension has regressed, but she has not been recatheterised. The data suggest that there is a group of patients with a high resistance, an apparently benign histological picture, and a poor prognosis. This group is missed if lung biopsy specimens are classified by the Heath-Edwards grading alone.

It could be argued that because of the poor prognosis patients with a lowest resistance of $>6$ units should not be offered operation irrespective of the lung histology. None the less, if it is decided that such patients should have an operation, a lung biopsy would need to be performed in all children with a resistance of $>6$ units to distinguish the "benign" group from those with disease that is late grade III or worse, who by any criteria are inoperable. Many patients in this "benign" group need to be studied to see whether they really should be offered corrective operation.

Any conclusions based on a selected series of this diversity must be tentative. Many children with congenital heart disease have a low pulmonary vascular resistance, never have a lung biopsy, and have a smooth postoperative course. In children in whom pulmonary vascular disease is suspected clinically, however, accurate measurement of pulmonary vascular resistance, combined in certain cases with lung biopsy, gives essential information for rational decision making.
$A B, S G H$, and $A A H$ are supported by the British Heart Foundation. We thank Dr J J Bowyer for permission to include data from two cases.

\section{References}

1 Hallidie-Smith KA, Hollman A, Cleland WP, Bentall $\mathrm{HH}$, Goodwin JF. Effects of surgical closure of ventricular septal defects upon pulmonary vascular disease. Br Heart J 1969;31:246-60.

2 Marcelleti C, McGoon DC, Danielson GK, Wallace RB, Mair DD. Early and late results of surgical repair of truncus arteriosus. Circulation 1977;55:636-41.

3 Nihill MR, McNamara DG. Magnification pulmonary wedge angiography in the evaluation of children with congenital heart disease and pulmonary hypertension. Circulation 1978;58:1094-106.

4 Heath D, Edwards JE. The pathology of hypertensive pulmonary vascular disease. Circulation 1958;18: 533-47.

5 Rabinovitch M, Haworth SG, Castaneda AR, Nadas AS, Reid LM. Lung biopsy in congenital heart disease: a morphometric approach to pulmonary vascular disease. Circulation 1978;58:1107-22.

6 Haworth SG, Hislop AA. Pulmonary vascular development: normal values of peripheral vascular structure. Am J Cardiol 1983;52:578-83.

7 Davies NJH, Denison DM. The measurement of metabolic gas exchange and minute volume by mass spectrometry alone. Respir Physiol 1979;36:261-7.

8 Davies NJH, Shinebourne EA, Scallan MJ, Sopwith TA, Denison DM. Pulmonary vascular resistance in children with congenital heart disease. Thorax 1984;39:895-900.

9 Bush A, Busst CM, Booth K, Knight WB, Shinebourne EA. Does prostacyclin enhance the selective pulmonary vasodilator effect of oxygen in children with congenital heart disease? Circulation 1986;74:135-44.

10 Bush A, Busst CM, Knight WB, Shinebourne EA. Cardiovascular effects of tolazoline and ranitidine. Arch Dis Child 1987;62:241-6.

11 Haworth SG. Pulmonary vascular bed in children with complete atrioventricular septal defect: relation between structural and hemodynamic abnormalities. Am J Cardiol 1986;57:833-9.

12 Haworth SG. Pulmonary vascular disease in ventricular septal defect: structural and functional correlations in lung biopsies from 85 patients, with outcome of intracardiac repair. J Pathol 1987;152:157-68.

13 Haworth SG, Radley-Smith R, Yacoub M. Lung biopsy findings in transposition of the great arteries with ventricular septal defect: potentially reversible pulmonary vascular disease is not always synonymous with operability. J Am Coll Cardiol 1987;9:327-33.

14 Kappagoda CT, Greenwood P, Macartney FJ, Linden RJ. Oxygen consumption in children with congenital diseases of the heart. Clin Sci 1973;45:107-14.

15 Kappagoda CT, Macartney FJ. Effects of environmental temperatures on oxygen consumption in infants with congenital disease of the heart. Br Heart $J$ 1976;38:1-4.

16 Fried R, Falkovsky G, Newburger J, et al. Pulmonary arterial changes in patients with ventricular septal defects and severe pulmonary hypertension. Pediatr Cardiol 1986;7:147-54.

17 Juaneda E, Haworth SG. Pulmonary vascular disease in children with truncus arteriosus. Am J Cardiol 1984;54:1314-20. 